
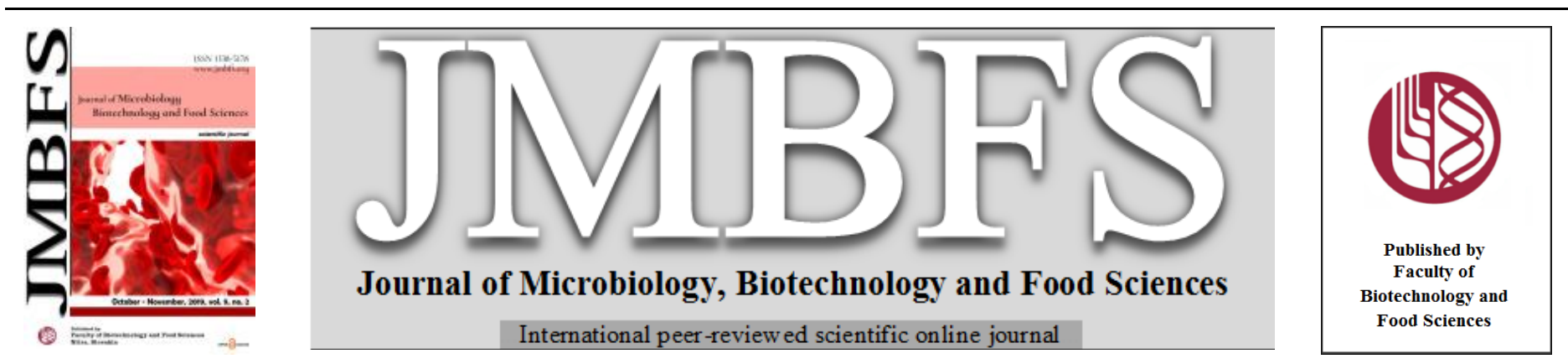

\title{
A FREEZE-DRIED, VIABLE, DISPERSED AND STABLE FORMULATION OF THE "LIQUID INTRA-VESICAL IMMUNOTHERAPY BCG MOREAU ${ }^{\circledR}$ FINLAY"
}

\author{
Ydalis Griñan Bell ${ }^{1,2}$, Isis García H. ${ }^{2}$, Tamara Hernández Z. ${ }^{1}$, María Elena Sarmiento GSM ${ }^{3}$, Armando Acosta Domínguez ${ }^{3}$, \\ Elizabeth Aznar Gonzalez ${ }^{1}$; Martha Carralero Tamayo ${ }^{2,4}$, Concepción Campa Huergo ${ }^{1}$, Lukas Hleba ${ }^{5}$, Mohammad Ali Shariati $^{6 *}$, \\ Muhammad Imran ${ }^{7}$, Sergey Plygun ${ }^{6,8,9}$, Alexy Laishevtcev ${ }^{6,10}$, V.Gustavo Sierra González $^{4 * *}$
}

\author{
Address(es): \\ ${ }^{1}$ Finlay Institute for Vaccines. Ave. 27 No. 19805. La Coronela, La Lisa; PO Box 16017; Postal Code 11600, Havana, Cuba. \\ ${ }^{2}$ Biological Products Enterprise "E.P.B. Carlos J. Finlay"; Vía Blanca and Palatino, Havana, Cuba. \\ ${ }^{3}$ Universiti Sains Malaysia. Institute for Research in Molecular Medicine. George Town. Malaysia. \\ ${ }^{4}$ BioCubaFarma. Biotechnological \& Pharmaceutical Industries Group. Ave Independencia No 8126. E/ Calle 100 y Boyeros, Havana, Cuba. \\ ${ }^{5}$ Department of Microbiology, Faculty of Biotechnology and Food Sciences, Slovak University of Agriculture in Nitra, Nitra, Slovak Republic. \\ ${ }^{6}$ Laboratory of Biocontrol and Antimicrobial Resistance, Orel State University Named After I.S.Turgenev, 302026 Orel, Russia. \\ ${ }^{7}$ University Institute of Diet and Nutritional Sciences Faculty of Allied Health Sciences, The University of Lahore-Lahore, Pakistan \\ ${ }^{8}$ European Society of Clinical Microbiology and Infectious Diseases, Basel, 4051, Switzerland \\ ${ }^{9}$ All Russian Research Institute of Phytopathology, Moscow Region, 143050, Russia. \\ ${ }^{10}$ Federal Research Center - All-Russian Scientific Research Institute of Experimental Veterinary Medicine named after K.I. Skryabin and Y.R. Kovalenko of the \\ Russian Academy of Sciences, Moscow, 109428, Russia.
}

*Corresponding author: shariatymohammadali@gmail.com;gsierra6352@gmail.com, gsierra@oc.biocubafarma.cu

doi: 10.15414/jmbfs.2020.9.5.1023-1028

ARTICLE INFO

Received 19. 7. 2019

Revised 5. 12. 2019

Accepted 13. 12. 2019

Published 1. 4. 2020

Regular article OPEN $\partial_{\text {ACCESS }}$

\begin{abstract}
The current study designed to obtain, execute and test a freeze-drying protocol for the preparation and a better storage conservation of the live attenuate Mycobacterium bovis BCG-Moreau-Finlay, fundamental element for the immunotherapy against bladder carcinoma, passed successfully all trials. The new lyophilized formulation also reduces the in vivo toxicity compared to present BCG liquid preparation by means of lowering dose needed for the treatment. The second re-seeding of the Moreau Rio de Janeiro sub-strain of Mycobacterium bovis BCG (pBCG Moreau); was sub-cultured in the Sauton Synthetic Medium (SSMII), previously maintained in Seed Lot Systems and harvested during the logarithmic growth phase. Basic Bacterial Suspension (BBS) was then prepared, homogenized and stabilized by freeze-drying in vehicle A, compare to vehicle B. By means of Thin Layer Chromatography (TLC) was realized the comparative quality control of the (BBS) preparation before and after lyophilisation procedure of the final product. A high (\%) colony count measure in Ogawa medium and average survival of $50.4 \%$ (Heat stability over the time). Additional values as $(0.75-0.95 \%)$ were obtained for the ranks of dispersion using Zieln Nielsen and the Dubos Methods. The integrity/vitality oscillated from 67.8 to 68.5 (\%) measured by oxygen consumption, the residual humidity indicators from 73 to $74(\%)[\mathrm{BBS}]$ and the accepts organoleptic properties designed all aftermaths concern the in vitro assays required by World Health Organization (WHO) standards for BCG intra-Vesical final product. A freeze-dried "Onco BCG Moreau - Finlay" formulation was successfully produced and has many "in vitro and in vivo test" practical and theoretical advantages when it compared to the current liquid preparation, such as the best preserving BCG biological properties and reducing the dose of product required for treatment.
\end{abstract}

Keywords: BCG Moreau sub-strain, bacillus Calmette-Guérin (BCG), intra-vesical immunotherapy, anti-tumours products, viability, dispersion - freeze- drying

\section{INTRODUCTION}

The effectiveness of treatment with liquid or freeze-dried formulations of the bacillus Calmette-Guérin (BCG) designed at immunotherapy against superficial bladder transitional cell carcinoma (TCC), be subject to on which sub-culture and the stabilization - production methods are used. The conditions are needed to achieve better anti-tumours adjuvant effects from intra-vesical immunotherapy with Mycobacterium bovis BCG or bacillus Calmette-Guérin (BCG) (Calmette et al., 1921; Zbar and Rapp, 1974; Morales et al., 1976; Vázquez-Lavista, 2007).

In 1924, first attenuated strains that are used for immunization against tuberculosis (TB) was distributed (Cataldi et al., 2010) and the dissimilar methods used to produce sub-cultures has resulted in multiple genetic changes or natural selection concluded in many divergent BCG sub-strains now in use (Osborn, 1983). All include Pasteur, Tokyo 172, Tice, Montreal, Connaught and Moreau of Rio de Janeiro, Brazil (Gheorghiu, 1990; Hayashi et al., 2010).

Therefore, in 1966 WHO suggested the minimization of genetic changes using the Seed-Lot System (Johannes, 1966) and stabilization through freeze-drying for preservation (Gheorghiu et al., 1996; Jin et al., 2006). In the procedure the materials are first frozen and later dried by vacuum sublimation and the resulting product depends on the lyo-protector vehicle, the age and metabolic characteristics of the culture and the recovery medium used. The methods are useful because it produces little losses, it yields a soluble product that is readily hydrated and it maintains the vulnerable biological BCG vaccine strains parameters, including the identity, viability, integrity and the others characteristics (Cataldi et al., 2010; Benito Adolfo et al., 2013).

In addition, bigger social scientific impact containing the bacillus as anti-tumour therapeutic products developed (Calmette $\boldsymbol{e t}$ al., 1921; Zbar and Rapp, 1974; Morales et al., 1976) has support the attention on the new subculture and manufacture methods designed for anti-tuberculosis vaccines (Calmette $\boldsymbol{e t}$ al., 1921; Zbar and Rapp, 1974; Cataldi et al., 2010). Now it is possible to produce liquid or freeze-dried formulations from BCG with appropriate viability, dispersion and integrity characteristics that improve their clinical utility though retaining the effectiveness when it used in the treatment of superficial bladder transitional cell carcinoma (TCC) (Calmette et al., 1921; Zbar and Rapp, 1974; Morales et al., 1976; Lugosi, 1992). 
The quality characteristics are linked especially to the stabilization method and the BCG sub-strain used (Gheorghiu, 1990; Gheorghiu et al., 1996; Hayashi $\boldsymbol{e}$ al., 2010). The first topic about durability over the time (Gheorghiu M, Lagranderie $M$ and Balazuc AM 1996). and the specific sub-strain; their viability, integrity, minimum effective dosages and protective efficacy in vivo (Mack and Frickk, 1995; Noriko et al., 2005; Gomes et al., 2011; Benito Adolfo et al., 2013). The diversity of products existing include: The Onco BCG TICE $®$ Licence No. 1747 and Vejicur ${ }^{\circledR}$ developed by the Organon Laboratories, using the sub-strain Tice, TICE ${ }^{\mathbb{B}}$ and RIVM from the United States (Benito Adolfo et al., 2013); the Connaught BCG from Canada (Mack and Frickk, 1995); the Tokyo $172 \AA$, based on the sub-strain BCG Tokyo 172 (Noriko et al., 2005) and the Liquid Intra-vesical BCG Moreau, "EPB, Carlos J. Finlay®" product, manufactured with the Moreau sub-strain Rio de Janeiro, Brazil (Gomes, 2011). This liquid preparation was demonstrated to be effective, but over the time there were some reports of toxicity problems by instability of the product refers the bacterium death, because BCG it is a live attenuated vaccine (Cataldi et al., 2010). The freeze-dried formulation presented here was developed as a solution assuring a long-term effectiveness during quality control trials and it's safe delivery (NC, 1988; WHO, 2011; Griñan Bell et al., 2001) The current study was used to design the freeze-dry formulation as a viable, disperse and stable form in order to substitute the liquid formulation of the Onco BCG product. To achieve that goal, we have been using the following protocol.

\section{MATERIAL AND METHODS}

Preparation of four lots of therapeutic Onco BCG Moreau dried product in vehicle $\mathrm{A}$ and $\mathrm{B}$.

\section{Materials}

Strain

Mycobacterium bovis BCG sub-strain Moreau Rio de Janeiro (pBCGM), (Secundary Seed Lot System 1978), from Copenhagen, Denmark, Internationa Center for the Production and Quality Control of the Freeze-dried BCG Vaccine; kept under the Seed Lot System propagated in the culture medium Sauton Potato (S-P) (NC, 1988; Gomes et al., 2011).

Sauton Synthetic Medium (SSM) (Van Deinse and Seneenchal, 1955), this medium used to obtain the individual surface layer of the microorganisms or the first re-seeding (SSMI) and second re-seeding (SSMII).

\section{Methods}

The first re-seeding of the BCG Moreau Rio de Janeiro sub-strain in SSM (I) (Van Deinse and Seneenchal, 1955; Gomes et al., 2011) originating from the BCG Moreau seed lot system (Johannes, 1966). It was first grown in the Sautón Papa (S-P) medium and subculture statically in a Memmert incubator (Germany) at $37^{\circ} \pm 05$ for periods ranging from 7 to 21 days; it was then aseptically transferred to the surface of other $250 \mathrm{ml}$ Erlenmeyer flasks containing $100 \mathrm{ml}$ of the SSM (II) medium.These flasks were incubated for 7 to 14 days until the culture layers were obtained (II) (Mack and Frickk, 1995). Following incubation, they were submitted to the selection criteria described below:

\section{Seed control (SSMII)}

For culture identity, we used the Ziehl Nielsen technique (WHO, 2011), traditional pH determination (Griñan Bell et al., 2001), electronic transmission microscopy (Kellenber and Ryter, 1958), and a TLC metabolic analysis of the culture to select the homogenization and lyophilisation vehicles (Martínez Ileana' Padrón María et al., 2005).

\section{Electronic transmission microscopy}

The bacterial suspensions Mycobacterium bovis (pBCGM) second re-seeding of the BCG Moreau sub-strain, harvested at the growth phases of 7, 8, 14 and 21 days (Mack and Frickk, 1995) and their BCG control were treated with a modification of the Ryter and Kellenberger technique (Kellenber and Ryter, 1958). After this, they were kept frozen in a resinous material overnight to produce the hardening or polymerization of it. Then using post-contrast of uranyl - lead and ultra-thin slices were made with the Ultrotome III LKB Equipment. Finally, the preparations were observed through the electron microscope JEM100 S - JEOL, belonging to National Research Center (CENIC).

Metabolic analysis of the BCG culture before and after freeze- drying procedure

The samples of pBCGM cultures (SSM II) (Goms, 2011) submitted to mechanical and thermal stress together with the ampoules of freeze-dried pBCGM in vehicles A and B were processed twice with SSF by washing in a BECKMAN centrifuge, Allegra 21, Germany. After the second centrifugation, the supernatant was discarded and the pellet obtained was resuspended in $70 \%$ ethanol for 1 hour; and afterwards, at $15000 \mathrm{x} \mathrm{g}$ for 5 minutes, and lastly the technique described below was carried out.

\section{Thin layer chromatography (TLC)}

For to determine the regression curves (volume of the stains against the amount of the standards) $(\mu \mathrm{g})$ and of the pBCG Moreau cultures before, and after freezedrying. TLC SILICA GEL 60 F-254 (5 x 20) cm (Merck, Germany) were used; activated at $110^{\circ} \mathrm{C}$ for $30 \mathrm{~min}$. Then: in system $\mathrm{A}$, we applying $2 \mu \mathrm{L}$ of the standard solution of fructose, glucose, xylose, lactose, galactose, manose, maltose and trehalose (Sigma, USA) and the concentrations of samples of BCG product between 4 to $12 \mu \mathrm{l} / \mathrm{L}$. They were quantified using the running System (2), with the solvent formed by 2-propanol/ acetone/ $0.1 \mathrm{M}$ lactic acid and the intensifying agent of diphenylamine/aniline/phosphoric acid at a temperature range of 18 to $20^{\circ} \mathrm{C}$ (Griñan Bell et al., 2001), (4) Preparation and quality control of four basic bacterial suspension (BBS) lots. Anhydrous-biosis by Freeze-drying. Comparative evaluation of results before and after lyophilisation procedure.

\section{Preparation of four basic bacterial suspension lots}

Afterwards, the sub-cultures pBCG Moreau developed on the Sintetic Sauton Media (SSM (II) (Van Deinse and Seneenchal, 1950) were selected according to the values of pH (Griñan Bell et al., 2001) and electron microscopy test; they were filtered through a Birkhang funnel (NC, 1988) and homogenized with stainless steel beads $2.5 \mathrm{~mm}$ diameter in vehicles A and $\mathrm{B}$, to obtain a basic suspension of the BCG Moreau containing $50 \mathrm{mg}$ of the semi-dry mass $/ \mathrm{mL}$ (w/v) of the vaccine (Liquid suspension BCGM vaccine) (NC, 1988). The material thus prepared was stored under refrigeration, between 2 and $8{ }^{\circ} \mathrm{C}$ protected from the light afterward the following test was carried out.

\section{Anhydrous-biosis by Freeze-drying procedure}

A total of $10 \mathrm{~mL}$ of $50 \mathrm{mg} / \mathrm{mL}$ bacterial suspensions corresponding to the therapeutic preparations onco pBCGM A (Defined mixture of mono sodium glutamate (MSG) Pure for Analysis (PA) Merck + trehalose Pure for Analysis (PA) Sigma, USA and its control pBCGM B (mono sodium glutamate (MSG) Pure for Analysis (PA) Merck, Germany 1.5\%) Were washed four times with phosphate buffer $\mathrm{pH} 7.38$ during 5 minutes each one, in centrifuged MettlerToledo, Models FE 20, and Switzerland. The supernatant was then discarded and the remaining pellets obtained were resuspends in amount sufficient for (CSP) for vehicle A (pBCGM) (A) $(\mathbf{N C}, \mathbf{1 9 8 8})$ and $(\mathrm{CSP})$ of $1.5 \%$ sodium glutamate for case of pBCGM (B), to obtain the bacterial suspensions of $50 \mathrm{mg} / \mathrm{mL}(\mathrm{w} / \mathrm{v})$ corresponding to the therapeutic preparations "Onco pBCG Moreau Finlay (A or B)". Then those were placed in the neutral amber glass ampoules of $10 \mathrm{~mL}$ and aliquots $2.5 \mathrm{v} / \mathrm{v}$ each vial. They were frozen at $-120{ }^{\circ} \mathrm{C}$ on the shelves of a Usifroid Lyophilizer Machine, Model SMJB and the freeze-dry procedure was started for a period of 18 to 24 hours (Jin et al., 2011). At the end of it, the ampoules were sealed under appropriate vacuum condition and stored at $4{ }^{\circ} \mathrm{C}$, protect from the light before submitted them to the different test describe above.

\section{Evaluation of the quality characteristics of the bacterial suspensions before and after freeze-drying}

\section{Determination of the vitality or germination capacity in Dubos medium}

Then, under laminar flow, was added $15 \mathrm{ml}$ of Dubos solid culture medium (Dubos, 1950) plus $5 \mathrm{ml}$ fraction V of bovine albumin PA Sigma USA, and rapidly poured into the Petri dishes $100 \times 13 \mathrm{~mm}$ to left to solidify. The total content of the plates was divided into $2 \mathrm{~cm}^{2}$ segments and transferred to slides. These segments medium was identified and inoculated with one drop of sample the (BBS) and the others with the freeze -dried product. after that were placed into the Petri dishes protected with the slide cover and keep on a sterile atmosphere of diluted Sauton medium (1+3) (Van Deinse and Seneenchal, 1950). The plates were incubated in a Mermert incubator (Germany) at $37+05^{\circ} \mathrm{C}$, for a period of 24 to 92 hours, protected from the light and from drying during which the readings were made by observations with an optical microscope. Cellular demand for oxygen, calculated in a Warburg Respirometer, according to the technique of Umbreit $\boldsymbol{e t}$ al. (1972). On $25 \mathrm{~mL}$ Erlenmeyer flasks, we added $0.5 \mathrm{~mL}$ of the second re-seeding of the pBCG Moreau sub-strain and $10 \mathrm{~mL}$ of the modified phosphate buffer solution (10X); $0.5 \mathrm{ml}$ of magnesium sulphate PA; 0.5 of calcium sulphate PA and 0.05 of ferric chloride PA all of these Merck, Germany. Later sterile distilled water was added into another similar $25 \mathrm{ml}$ flask as the blank and the Electroquimical Transducer Oxygen Pressure $\left(\mathrm{pO}_{2}\right)$ detection was connected to the Udesverde Bartha Respirometer and place into incubator shaker chamber, New Brunswick Scientific Co. INC, USA, at $37+05^{\circ} \mathrm{C}$ for a period of 1-4 days and started the readings of the samples of pBCG Moreau (A or B) (liquid and lyophilized) for revealing oxygen cell consumption expressed in $\mu \mathrm{LO}_{2} / \mathrm{mg} / 120$ hours. 
Each of the bacterial suspensions of $50 \mathrm{mg} / \mathrm{mL}$, vehicle A and vehicle B and their corresponding freeze-dried samples were first dilute a concentration of $1 \mathrm{mg} / \mathrm{mL}$ BCG Moreau vaccine vehicle A or B in Sauton medium diluted $(1+3)$, before performing a serial double dilution between 40,000 to 160,000 for the liquid samples and between 10,000 and 40,000 for the lyophilised samples. They were seeded in the amount of $100 \mu \mathrm{L}$ in $200 \times 13 \mathrm{~mm}$ culture tubes containing the Ogawa medium. They were incubated at $37.5^{\circ} \mathrm{C}$ in a Menmert incubator (Germany) protected from natural light and from drying, for periods of 21 to 28 days. After ending this incubation period, we statistically calculated the colony forming units and percentages of survival in millions of cells $/ \mathrm{mL}$, according to the WHO Technical Guide 77, 9 (WHO, 2011).

\section{Statistical analysis}

The current results are subjected to statistical program SPSS version 9.0 on Windows and to determine the analysis of variance (ANOVA). If there were significant differences, the Sheffé method would be used later for differences between means (Eric et al., 2012).

\section{Results and Discussion}

Details of method in what way the pBCGM subculture seed to get the BBS are shown in Table 1. These describe the four passes of the original seed made in the Sauton - Papa medium S-P (1-4), that came from the Seed Lot System, which were planned to guarantee the biological safety of the sub-culture (NC, 1988; WHO, 2011) and made it possible to collect the Synthetic Sauton medium (SSMII) within a period of 6-8 days (log phase).

Table 1 General manufacturing technique of the Basic Bacterial Suspension and Freeze-drying of the on "ONCO BCG Moreau- Finlay"

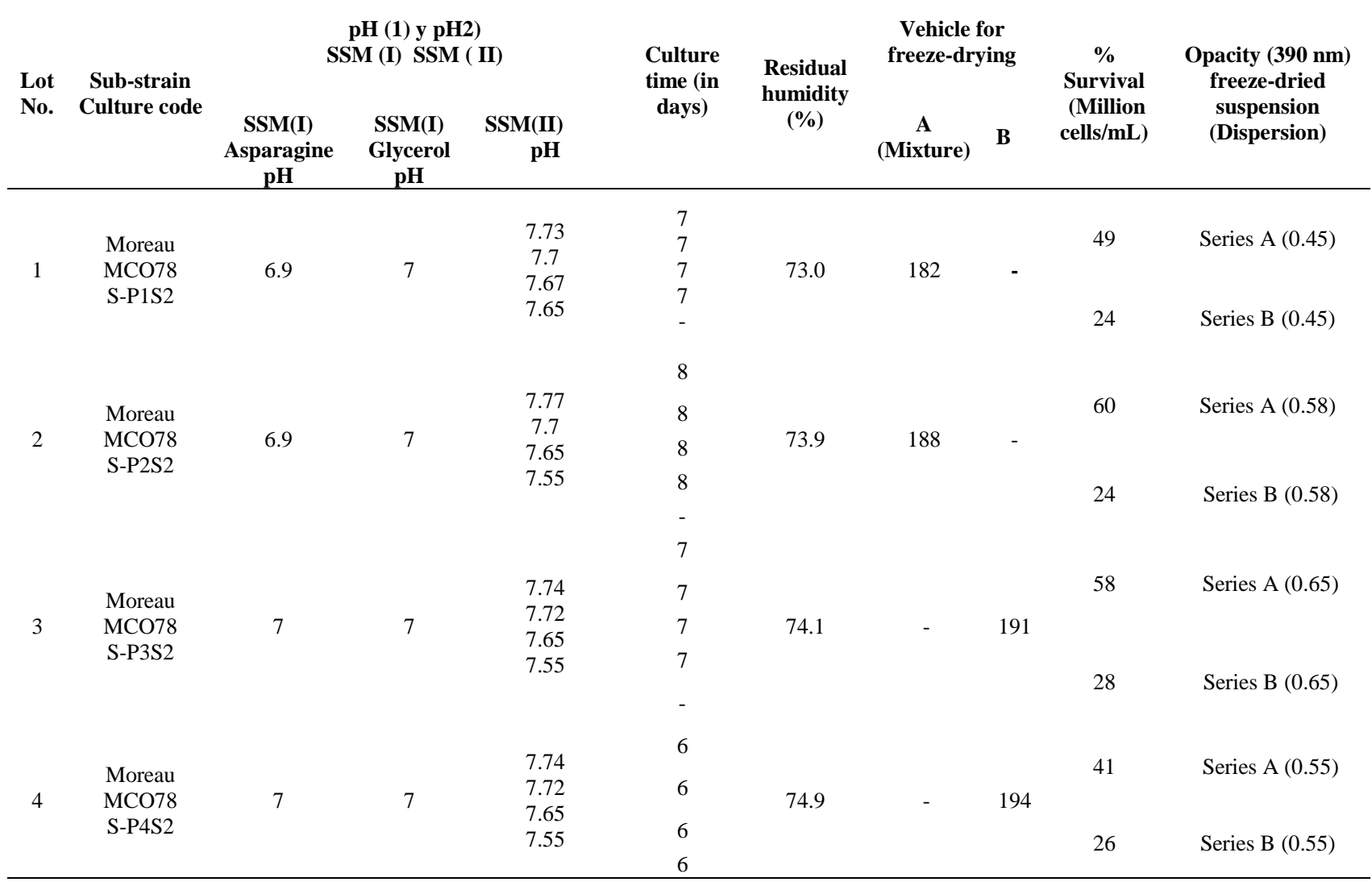

This was found to be an optimum age for the future lyophilisation procedure. The traditional $\mathrm{pH}$ values obtained during the same bacterial development phase (Griñan Bell et al., 2001) is shown in Figure 1, too.

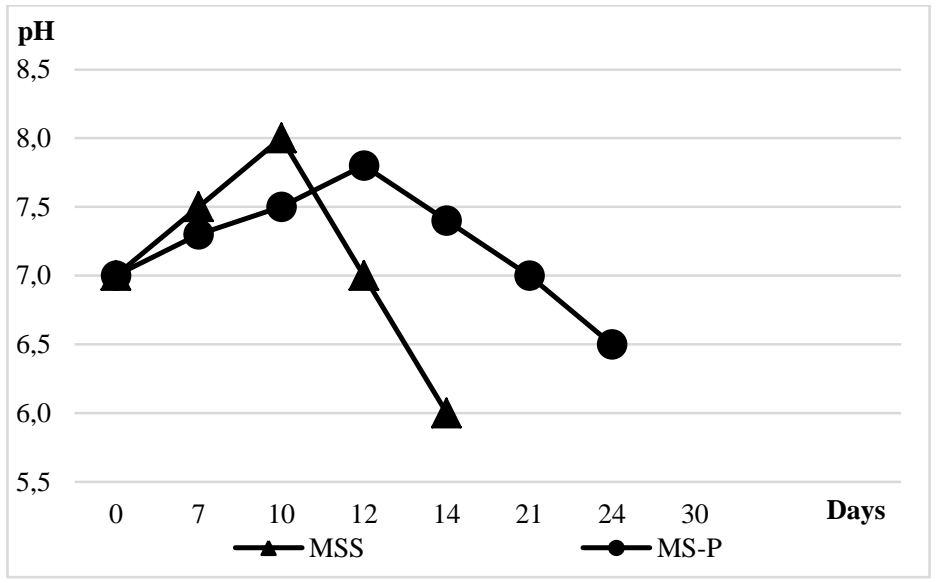

Figure 1 Curves of $\mathrm{pH} /$ culture time for $\mathrm{pBCGM}$, developed in the liquid culture media: SSM and MS-P

At the opening, the pBCGM culture were range around neutrality $(6.8-7.0$ and 7.0 - 7.5). Advanced the time culture in (SSM) media, between days 10 and 12, it ranks of $\mathrm{pH} 8.0-8.2$. Finally, for the days 12 to 14 ; there were rapid changes near acidic $\mathrm{pH}$ place concerning (6.4 -5.8); analogous as in (S-PM) media, but on the contrary about to $14-21$ days. After that pBCGM sub-culture showing the decline growth curves phase, the death of microorganisms occurs and cellular lysis is observing; created by the excretion within the culture medium of different materials with an acid metabolic reaction, so as tuberculin and others proteins reported by some researchers, that are not of interest in this study; however, there are important for the previous lyophilisation procedure selection (Jin et al., 2011).

Subsequently if the Cuban liquid product will prepare with this weakness sub cultures (NC, 1988; WHO, 2011; Griñan Bell et al., 2001), certainty they will not be valuable at the age required to maintain good viability and integrity BCG Moreau final preparation after freeze drying procedure (Lugosi, 1992). The above significant aspect refers in Figure 1, was later confirmed in the comparative cellular ultra- structures of pBCG Moreau subculture (Figure 2); where the declining grow curves phase between $14-21$ days (Figure 2B), shown the cellular bacterial lyses' and the poor probability of this pBCGM culture of successfully using it in the mentioned events. 


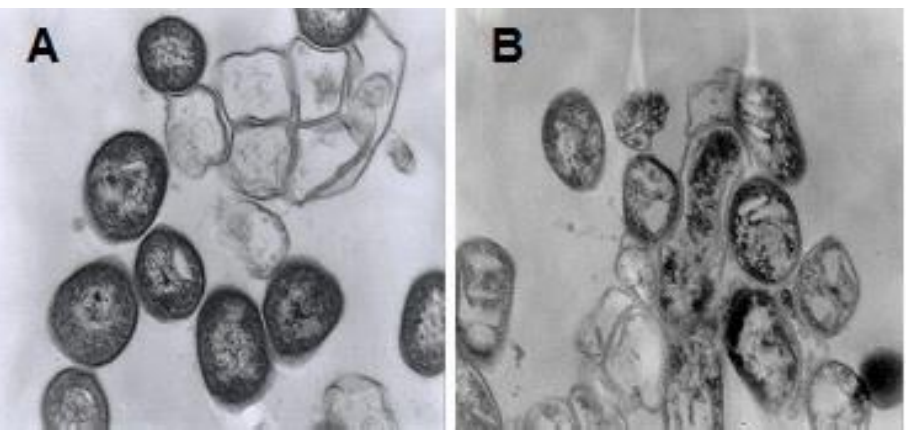

Figure 2 A) Ultra-micrograph [60 000x] of pBCGM between 7-8 days of growth [log phase] in SSM and MS-P. B) Ultra-micrograph [60 000x] of pBCG cultures between 14 - 28 days [declining phase] in SSM and MS-P.

An important contribution of this research as the guideline concerning the best harvest time for using it before the formulation of the dried BCG Moreau immunotherapeutic products. For to continue with on the assessment of the results shown in table 1 , we place in the quality control of the process carried out in the four basic suspensions produced from pBCG Moreau before and after the freeze-drying, the average percentages of residual humidity of the bacterial cake were of 73.0 - 73.9 dry water contain (WHO, 2011). The opacity test in terms of absorbance ranged of (DO) from $0.45-0.58$ and all the way through the determinations of the CFU/mL $/ 10^{6}$ (WHO, 2011). The first two factors studied are related to the analyses of the levels of dispersion for the future dried preparation (NC, 1988). Therefore, some authors suggest that the correct elimination of the majority remaining liquid in the manufacturing stage is vital, for the best finally during the traumatic changes in condition that the bacillus will submit yourself to in the anhydrous-biosis procedure (Jin et al., 2011). And It is also important for the future protective efficacy of the final BCGM product; since the high grade of dispersion cell as the quality control given that it, provides the microorganism with a better performance as an adjuvant in vivo test (Morales $\boldsymbol{e}$ al., 1992; Eric et al., 2012).

Of equal importance is the homogenization technique employed. Here we used mechanical method (NC, 1988) (see Table 1) and its correct implementation is vital for the protective efficacy of the in vivo product, since it is essentially due to the fact that as more disperse the BCG, further the contribution to its exact possibility to phagocyte the mentioned tumour cells (Eric et al., 2012), whereas giving a superior idea on the consistency and quality of the basic Suspension lots produced previous to obtaining the final lyophilized formulation (Jin et al., 2011).

Subsequently and for completing the quality control of the therapeutic product, the last essential factors analysed in this investigation the final test of viability count in Ogawa media (NC, 1988). It is directly interrelated to the comparative ending results of the drying formulation obtained after that and It is based on the vehicles of homogenization - lyophilisation monosodium Glutamate plus Threalose (A) or Glutamete of Sodium (B) select (Griñan Bell $\boldsymbol{e t}$ al., 2016), previous to carry out the metabolic analysis of the pBCG Moreau before and after freeze - drying. Next see in Figure 3(A) (before) the regression curves of the mentioned sugar patterns are shown, and in Figure 3(B), related to the metabolic performance of the individual seed cultures (MSSII) plus the result of the basic bacterial Suspension submitted to mechanical and thermal stress are exposed during the homogenization of the culture, before the lyophilisation procedure described in Figure 4. While in Figure 3C (after) the regression curves of the sugar patterns and in Figure 3D. the samples of dried product (after) lyophilisation procedures. Those are elements that (when including so as to), put in the necessary acknowledgment used adjacent before the freeze-drying study designed, in order to give enough evident about reduction of the stressing factors in BCG product during freeze-drying. Afterwards now we expected for a height number of colonies counting in Ogawa media (viability) and for a good integrity bacterial cell too (NC, 1988; Lugosi, 1992).
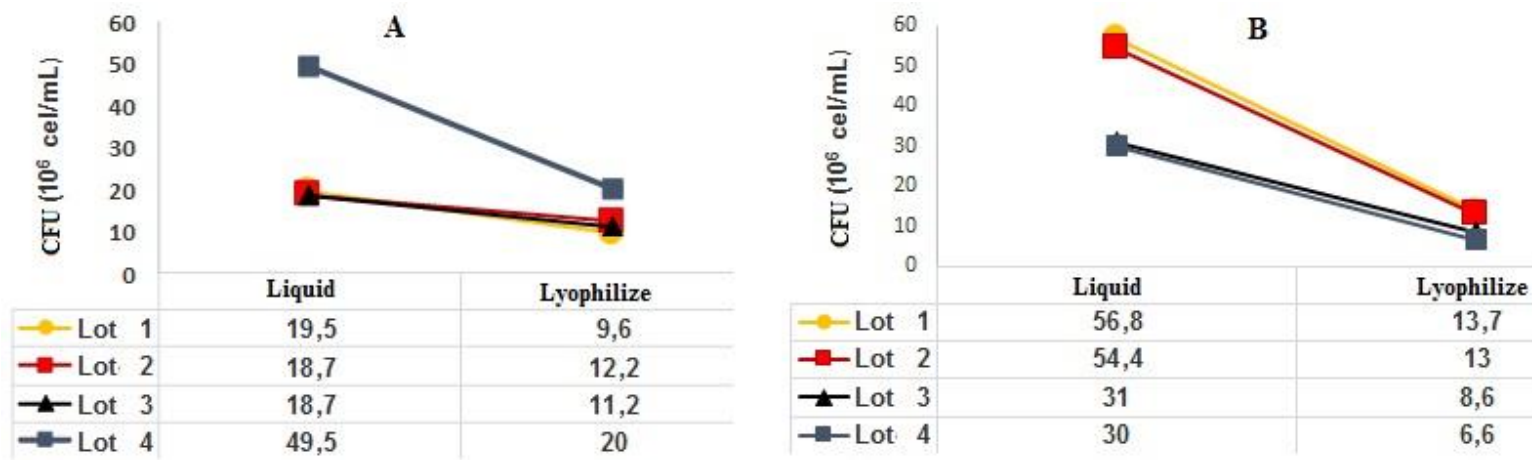

Figure 5 Cell viability of freeze drying depending on the vehicle
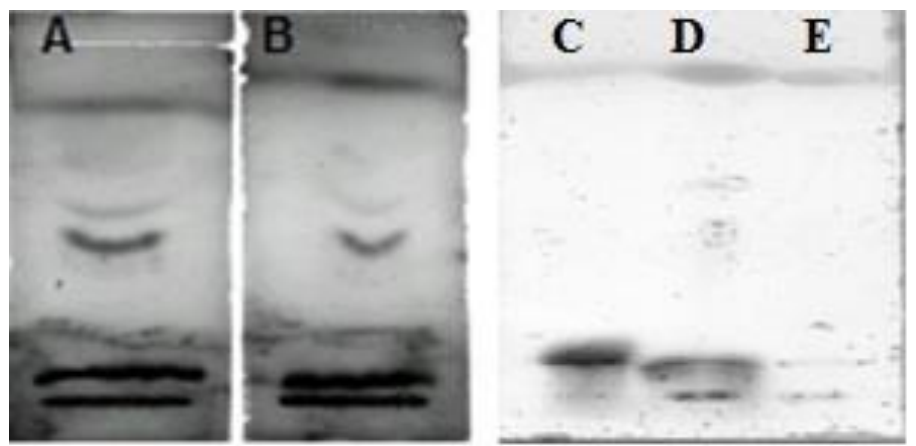

Figure 3 Detection of lyo-protective sugars incorporated to the structure of the (PBCGM). A and B (before freeze-drying). A) Reference solutions of fructose, glucose, xylose, galactose, manose, maltose, lactose and trehalose from Sigma (USA). B) Presence of glucose and trehalose in the samples of (pBCGM). C, D and E (after freeze-drying). C) Sugar reference solution. D and E). Incorporated sugars, found in the cellular structure according to the metabolic pathway of freeze- dried pBCGM product.

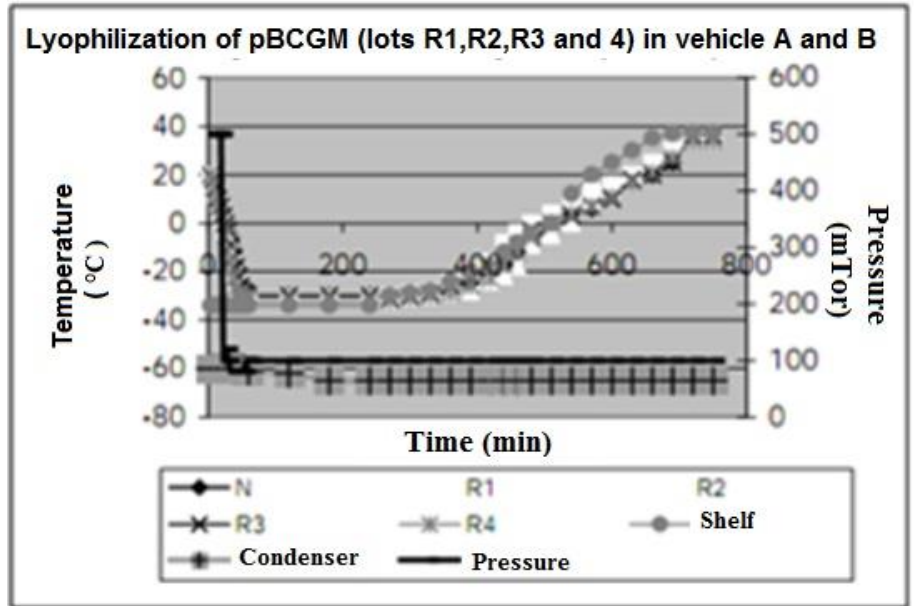

Figure 4 Lyophilization of pBCGM (R1, R2, R3 and R4 lot)

So as a result to knowledgeable about the preservation of viability and integrity since the perspective of the use of vehicles B, in conjunction with vehicle A (Griñan Bell et al., 2001; Griñan Bell et al., 2016), this work suggest: Even when mono sodium glutamate (MSG) is confirmed as an excellent stabilizer for the drying and protection process for the vulnerable biological parameters of the BCG (viability, stability and the factors involved in the genetic changes and protective efficacy of the vaccine), which agrees with reports from other researchers (Cataldi et al. 2010). This study demonstrated that when vehicle B is used alone, the viability indicators decrease notably at the end of freeze-drying compared to vehicle A (see Figure 5A). This occurs in spite of initial the procedure with the highest percentage of live cells (Figure 5B). This is completely justified by the excellent stabilizing action exerted by the MSG on the viability of the microorganism during the homogenization and the conservation 4-8 ${ }^{\circ} \mathrm{C}$. However, within the anhydrous-biosis procedure, as denoted in the results of Figure 3CDE and 7, the protective action developed by vehicle $\mathrm{B}$ was not sufficient. This is because the substance partly lacks the lyo-protective property of the cell membranes being found in the trehalose, as the reducing disaccharide used (Martínez Ileana' Padrón María et al., 2005; Jin et al. 2011) (Figure 3CDE) 
The marks obtained with the proposed formulation, on using the monosodium glutamate together with trehalose to form vehicle A (Griñan Bell et al., 2016) is then relevant, since it was demonstrated that if both were present during the different changes of state produced during freeze-drying (Martínez Ileana Padrón María et al., 2005; Jin et al., 2011), a considerable number of bacteria are benefitted because they receive good cross protection, in relation to cellular lysis and bacterial disintegration. This situation is observed in Figure 3 and 4 where it shows in lot 1 vehicle. The start of the freeze-drying process with a viability index in the Ogawa (NC, 1988) medium for the basic bacterial suspension (BBS) of $19.6 \mathrm{UFC} / \mathrm{mL}$ and of 9.6 in the final product for a survival rate of $49.0 \%$. However, again in lot 1 , but adding vehicle $\mathrm{B}$, the procedure started with $31.0 \mathrm{CFU} / \mathrm{mL}$ and ended with 8.6 , for a survival rate of $28.0 \%$. Other lots showed similar performance: $2(18-12,60 \%$; $54.4-13 ; 24 \%$ ); $3(18.7-11.2,58 ; 31-8.6 ; 28 \%)$ and $4(49.5-20,41 \% ; 30-6.6,26 \%)$

Table 2 Oxygen consumption in Liquid and Lyophilized pBCGM

\begin{tabular}{|c|c|c|c|c|c|}
\hline \multicolumn{3}{|c|}{$\begin{array}{l}\text { Oxigen consuption(OC) in "Liquid \& Lyophilized } \\
\text { preparations" of pBCGM (A) }\end{array}$} & $\begin{array}{l}\text { OC in " c ciquid } \\
\text { preparations pBCGM (B) }\end{array}$ & $\begin{array}{l}\text { \& } \text { Lyophilized } \\
\text { Vehicle (B) }\end{array}$ & $\begin{array}{l}\text { Survival } \\
\text { pBCGM(A) and } \\
\text { pBCGM(B) }\end{array}$ \\
\hline $\begin{array}{l}\text { Lot } \\
1 \mathrm{~A}\end{array}$ & $\begin{array}{l}\text { Vehicle (A) } \\
\text { Liquid } \\
230\end{array}$ & $\begin{array}{l}\text { Vehicle (A) } \\
\text { Lyophilized } \\
156\end{array}$ & $\begin{array}{l}\text { Vehicle (B) } \\
\text { Liquid }\end{array}$ & $\begin{array}{l}\text { Vehicle (B) } \\
\text { Lyophilized }\end{array}$ & $\begin{array}{l}\text { Survival \% } \\
67.8\end{array}$ \\
\hline $2 \mathrm{~A}$ & 216 & 148 & & & 68,5 \\
\hline 1B & & & 192 & 148 & 53,6 \\
\hline $2 \mathrm{~B}$ & & & 222 & 103 & 63,7 \\
\hline
\end{tabular}

Also, in regard to the germination rates in the solid Dubos medium (Dubos test) there was a fluctuation of $(0-75$ to $95 \%)$ for vehicle $A$ and $(0-50$ to $90 \%)$ for B (Figure 6). they were coincident, as denoted the similarity of the curves shown in Figure 3 and 4, which also refers about the regularity and consistency of the manufacture of the four immunotherapeutic BCG production lots. In spite of this, it is considered that although the trials of table II and Figure 3, 4 and 8 show only a non-significant qualitative measure $(\mathrm{p} \leq 05)$, concerning vitality and viability of the microorganism before and after freeze-drying, when this is making together with the determination in the Ogawa medium, the quality of the final product is undoubtedly unbreakable (NC, 1988; WHO, 2011; Griñan Bell et al., 2001). It is important to keep in mind that final CFU count and vitality of the preparation are the key quality control parameters of the preparation because on the level and consistency of such parameters depends the biological properties and final therapeutic effect of the product (NC, 1988). Different studies have reported the use of such parameters for comparing viability and cellular integrity of the bacillus before and after drying of the preparations (Gheorghiu, 1990; Lugosi, 1992), because they predict final survival and heat-stability as well as resistance against damages by freeze drying processes ${ }^{12}$. At the same time, these parameters offer the best criteria for evaluation of the quality indicators and the final assurance of expiry date of the product (NC, 1988; WHO, 2011; Griñan Bell et al., 2001; Griñan Bell et al., 2016).

\section{CONCLUSION}

We conclude that the new formulation of the freezed-dried product "Onco BCG Moreau - Finlay" proposed to replace the liquid preparation of the EPB Carlos J Finlay, has advantages over the second; because it will permit the use of lower doses in the treatments of patients based on the high levels of viability, dispersion - integrity and vitality achieved in said lyophilized formulation. Therefore, we expect less toxicity and greater effectiveness for intravesical treatment with the new formulation. The product maintains its stability for longer periods of time with living and intact cells necessary for antitumor therapy; That allows the extension of expiration dates, complete long quality control trials such as storage for long periods, perform more extensive clinical studies and improve the logistics functionality for safe distribution in hospitals located far from where the productive installations are based. The proposed lyophilization protocol showed to be robust and reproducible and we recommend it, to be used at the level of production.

Conflicts of Interest: The authors of this paper declare that there are no conflicts of interest. Intellectual property rights are registered as in references; Griñan Bell, Y. et al (2006)a and b.

Acknowledgments: Authors want to acknowledge the regulatory and methodological revision of the paper by Dr. Mohammad AS and his team. We

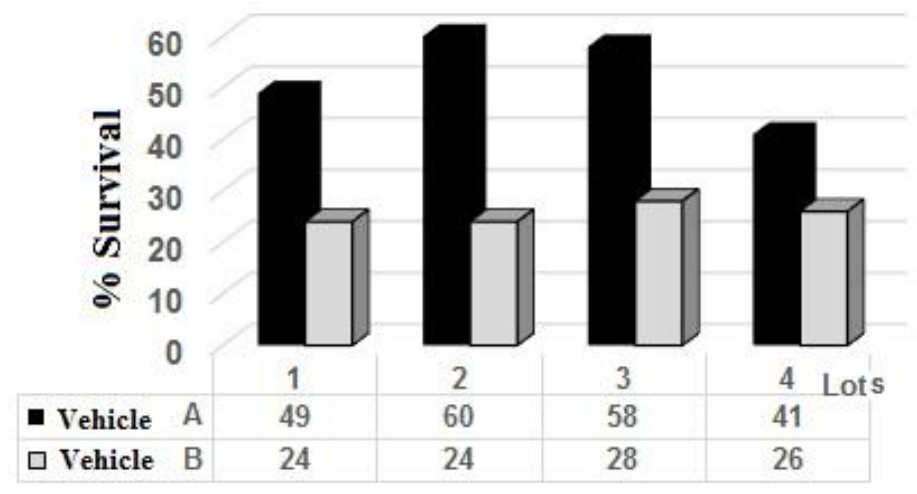

Figure 7 Percent of survival of freeze drying depending on the vehicle

In relation to the other controls, the oxygen consumption on the bottom part of Table 2 show the value oscillated between 67.3 and 68.5 for vehicle A and of 53 $6-63.7 \%$ for B. This demonstrated the permanence of the integrity and vitality of the bacilli before and after the drying procedure.

want to thank for their valuable collaboration regarding the bio statistical methods and procedures Dr Hector Bayarre Vea, from Victoria de Girón Faculty of Medical University of Havana, Cuba and Luís Izquierdo, BS of the Finlay Institute. Habana, Cuba. We would particularly like to acknowledge the work done by Dr. Angel Berto González Segredo from "EPB Carlos J. Finlay Enterprise" (now deceased) and to Javier Vassco, MSc. Griñan Bell's son. The first for his valuable contribution in BCG freeze-drying techniques used in Cuba and the second for to bring encouragement to this project.

\section{REFERENCES}

Benito Adolfo, S.F., Pilar, S.F., \& Benito Adolfo, S.G. (2013). Terapia Intravesical. Administración de BCG (Vejicur). Efectos adversos. Enfermería Docente, 100, 15-17.

Calmette, A., Boquet, A., \& Negre, L. (1921). Contribution a L'etude du bacille tuberculeux bilie. Ann Institut Pasteur, 192(35), 561-570.

Cataldi, A., Bigi, F., Mohd-Nor, N., Acosta, A., \& Sarmiento, M.E. (2010). The Art and Science or Tuberculosis Vaccine Development. UK: Oxford University Press, 56-162.

Dubos, R.J., \& Pierce C.H. (1950). Properties of a culture of BCG grown in liquid and solid media containing Twee 80 and the filtrate of heated serum. Am Rev Tuberc, 61, 66.

Eric, J., Ask E., \& Mark, R. (2012). Newton Michael A. O’Donnell, and Yi Luo Bladder. Cancer Immunotherapy: BCG and Beyond. Advances in Urology, 12.

Gheorghiu, M., Lagranderie, M., and Balazuc A.M. (1966). Stabilisation of BCG vaccines. Dev Biol Stand, 87, 251-261.

Gheorghiu, M. (1990). The present and future role of BCG vaccine in Tuberculosis Control. Biologicals, 18, 135-141. https://doi.org/10.1016/1045 1056(90)90025-u

Gomes L.H.F., Otto, T. D., Vasconcellos, E. A., Ferrao, P.M. Maia, R.M. Moreira, A. S., Ferreira, M. A., Castello-Branco, L. R. R., Degrave, W. M., \& Mendonca-Lima, L. Genome sequence of Mycobacterium bovis BCG Moreau the Brazilian vaccine strain against tuberculosis. Journal of Bacteriology, 193 5600 -5601. https://doi.org/10.1128/jb.05827-11.

Griñan Bell, Y., Campa Huergo, C., \& Acosta Dominguez, A. (2016a) Obtención y caracterización de una subcepa de Mycobacterium bovis BCG Moreau que contiene el gen opc de Nessseria meningitidis". Tesis de Maestría. Facultad de Biología, Universidad de La Habana. 2001

Griñan Bell, Y., Sierra González, G., Campa Huergo, C., Sarmiento San Miguel, M.E., \& Martínez Mota, I. (2016b). Sobre modelos experimentales «Aportes a la termo estabilidad del inmunoterápico BCGM cubano $\mathrm{y}$ al subcultivo recombinante rBCGM-5C, Documento Tesis Doctoral. "ICBP Victoria de Girón", Universidad de La Habana. Cuba. 
Hayashi, D., Takii, T., Mukai, T., Makino, M., Yasuda, E. (2010). Biochemical characteristics among Mycobacterium bovis BCG sub strains. FEMS Microbiol Letters, 306 (2), 103-109. https://doi.org/10.1111/j.1574-6968.2010.01947.x.

Jin, T.H., Nguyen, L., Qu, T., \& Tsao, E. (2011). Improved formulation and lyophilization cycle for $\mathrm{rBCG}$ vaccine. Vaccine, 29 (29-30), 4848-4852. https://doi.org/10.1016/j.vaccine.2011.04.056.

Johannes, G. (1966). The rationale of the use of the SEED-LOT SYSTEM for BCG: with a mathematical model simulating the displacement of the mother strain by mutant. Wld Hlth Org techn Rp Ser, 329.

Lugosi, L. (1992). Standardized viability test required for preventive, inmunomodulator and recombinant BCG vaccine. Dev Biol Stand, 77, 211-215.

Mack, D., \& Frickk, J. (1995). Low - dose bacilli Calmette Guerin (BCG)

Therapy in superficial hightrisk bladder Cancer: an fhase II study with the BCG Strain Connaught, Canada. British Journal of Urology, 75, 185187. https://doi.org/10.1111/j.1464-410x.1995.tb07308.x .

Martínez Ileana Padrón María, A., Acosta, M., \& Griñan, Y. (2005). Aplicación de métodos bioquímicos en la caracterización de antígenos vacunales, alérgenos y otras biomoléculas de origen bacteriano Revista CENIC. Ciencias Biológicas, 36.

Morales, A., Eidinger, D., \& Bruce, A.W. (1976). Intracavitary bacillus

Calmette- Guérin in the treatment of superficial bladder tumors. Jornal of Urology, 116, 180-3. https://doi.org/10.1016/s0022-5347(17)58737-6.

Morales, A., Curtis, N.J., \& Wilson, J. (1992). Dose response of BCG in the treatment of superficial bladder cancer. $J$ Urol, 147, 1256-1258. https://doi.org/10.1016/s0022-5347(17)37532-8.

Noriko, I., Ikuro, H., Ikuya, Y., \& Ichiro, T. (2005). Bacillus Calmette-Guerin Tokyo172 sub strain for superficial bladder cancer: Characterization and antitumor effect. The Journal of Urology, 173(5), 1507-1512. https://doi.org/10.1097/01.ju.0000154354.06892.ba.

NC. (1988). Medicamentos. Vacuna BCG Liofilizada. Especificaciones de calidad del proceso tecnológico y materias primas. Marzo 26-187.

Kellenber, E., Ryter, A., \& Sechaud, J. (1958). Electron microscope study of DNA containing plasms II. Vegetative and mature phage DNA as compared with normal bacterial nucleoids. Journal Biophys Biochem Cytol, 4, 671678. https://doi.org/10.1083/jcb.4.6.671

Osborn, T.W. (1983). Changes in BCG strain Tubercle. Tubercle, 64,1-3. https://doi.org/10.1016/0041-3879(83)90044-2.

Van Deinse, F., \& Seneenchal, F. (1950). BCG on Sauton's medium; effect of a long series of subcultures on the morphological and biological properties of BCG cultures. Bull World Health Organ, 2(3), 347-354.

Vázquez-Lavista, L.G. (2007). The bacillus Calmette-Guérin as immunomodulator in bladder cancer. Rev Invest Clin, 59 (2), 146-152.

WHO. (2011). Expert Committee on Specifications for Pharmaceutical Preparations. Forty-fifth report. Geneva, World Health Organization, (WHO Technical Report Series, No. 961.

Zbar, B., \& Rapp H.J. (1974). Immunotherapy of guinea pig cancer with BCG. Cancer, $\quad 34, \quad 1532-1540 . \quad$ https://doi.org/10.1002/10970142(197410)34:8+<1532::aid-cncr2820340827>3.0.co;2-h 